\title{
PENERAPAN GAYA GESEK PADA KEHIDUPAN MANUSIA
}

\author{
Imam Wahyu Hardiansyah ${ }^{1}$ \\ ${ }^{1}$ Institut Agama Islam Negeri Ponorogo 63492, Indonesia \\ Email: imamhard7@gmail.com
}

Diajukan: 18 January 2021; Diterima: 24 February 2021; Diterbitkan: 30 April 2021

\begin{abstract}
Abstrak: Terdapat macam-macam gaya yang mungkin dapat diterapkan di dalam kehidupan sehari-hari, salah satunya adalah gaya gesek. Tujuan artikel ini adalah untuk memberikan wawasan kepada para pembaca mengenai pengertian gaya gesek, macam-macam gaya gesek, serta penerapan gaya gesek dalam kehidupan manusia. Gaya gesek tersebut mencakup gaya dalam aspek yang menguntungkan dan gaya dalam aspek yang merugikan bagi kehidupan manusia.
\end{abstract}

Kata kunci: gaya gesek, gaya gesek statis, gaya gesek dinamis

Abstract: There are various styles that may be applied in everyday life, one of which is friction. The purpose of this article is to provide readers with insight into the meaning of friction, various types of friction, and the application of friction in human life. The frictional force includes a force in a beneficial aspect and a force in an adverse aspect for human life.

Keywords: friction, static friction, dynamic friction

\section{Pendahuluan}

Ilmu Pengetahuan Alam (IPA) adalah ilmu pengetahuan yang mempelajari hal-hal yang berkaitan dengan alam. Ilmu pengetahuan ini meliputi biologi, fisika, dan kimia. IPA dihasilkan dari suatu sikap ilmiah sehingga menghasilkan suatu produk ilmiah yang erat kaitannya dengan gejala-gejala alam. Setiap pembelajaran IPA memiliki pembahasan yang berkaitan dengan alam, baik yang menyangkut benda hidup, tak hidup, struktur kimia, ataupun teori-teori yang berkaitan dengan aktivitas sehari-hari.

Fisika adalah ilmu tentang zat dan energi, seperti panas, cahaya, dan bunyi. Fisika juga dapat dikatakan sebagai sebuah proses dan suatu produk. Proses artinya prosedur untuk menemukan fisika (fakta, konsep, prinsip,teori, atau hukum) yang dilakukan melalui langkah-langkah ilmiah. Berbeda dengan biologi yang mempelajari kehidupan dan organisme hidup dan kimia yang mempelajari mengenai unsur-unsur kimia dan sifat-sifatnya, fisika mempelajari gejala alam yang tidak hidup atau materi dalam ruang dan waktu. Banyak materi yang dapat dipelajari dalam fisika, tentunya memiliki kemungkinan besar yang berkaitan dengan kehidupan sehari-hari. Salah satunya adalah gaya.
Gaya adalah suatu tarikan dan dorongan yang diberikan kepada suatu benda sehingga benda mengalami perubahan posisi atau kedudukan (bergerak) serta berubah bentuk. Selain itu, gaya juga dapat diartikan sebagai suatu tarikan atau dorongan yang dikerahkan oleh sebuah benda terhadap benda lain. Gaya memilki banyak cabang, salah satunya adalah gaya gesek.

\section{Metode Penelitian}

Metode yang digunakan dalam penulisan artikel ini adalah kajian pustaka yaitu mengumpulkan buku-buku atau sumbersumber lain yang berhubungan dengan penerapan gaya gesek. Tujuan dari penulisan artikel ini adalah untuk memenuhi tugas Bahasa Indonesia serta menambah wawasan bagi penulis maupun pembaca mengenai gaya gesek. Harapan penulis adalah artikel ini dapat menambah pengetahuan dan wawasan terkait penerapan gaya gesek dalam kehidupan manusia.

\section{Hasil Penelitian dan Pembahasan \\ 1. Pengertian Gaya Gesek}

Gaya gesek merupakan gaya yang terjadi diantara dua benda yang yang saling bersentuhan. Sumarjono (2005:70) menyatakan bahwa gaya gesek adalah gaya yang berarah melawan gerak benda atau 
arah kecenderungan benda akan bergerak. Sedangkan menurut Riyadi (2019:8) gaya gesek adalah gaya yang ditimbulkan akibat permukaan benda yang saling bergesekan. Dari beberapa pendapat tersebut dapat disimpulkan bahwa gaya gesek adalah gaya yang disebabkan karena adanya gaya yang berarah melawan gerak benda akibat sentuhan antara dua benda.

Sejalan dengan itu, Salim (2017:51) berpendapat bahwa secara mikroskopis, gaya gesek disebabkan oleh interaksi melalui terbangunnya gaya ikat antara molekul-molekul yang berada dipermukaan suatu benda dengan molekul-molekul pada permukaan benda yang lain ketika keduanya saling bersentuhan. Benda yang dapat bersentuhan atau bergesekan ini dapat berupa benda padat, cair, dan gas. Gaya gesek antar benda padat yang dapat dijumpai dalam kehidupan sehari-hari adalah gesekan antara tanah dengan sepatu yang kita pakai. Antara benda cair dan padat juga dapat terjadi gaya gesek, misalya saat kita berenang, maka akan terjadi gaya gesek antara sang perenang dengan air. Begitu pula gaya gesek antara benda padat dengan gas. Misalnya gaya gesek yang terjadi pada pesawat terbang dan udara. Gaya gesek memliki arah gerak yang berlawanan dengan kecenderungan benda yang bergerak.

Gaya gesek dapat terjadi pada benda yang memiliki permukaan halus maupun kasar. Semakin halus permukaan benda, maka semakin kecil gaya geseknya. Sebaliknya, semakin kasar permukaan benda maka semakin besar gaya geseknya. Jadi dapat disimpulkan bahwa besar kecilnya gaya dapat disebabkan oleh halus atau kasarnya permukaan benda. Pada benda yang memiliki permukaan licin tetap dapat terjadi gaya gesek meskipun sangat kecil.

\section{Macam-Macam Gaya Gesek}

Gaya gesek tentunya masih dapat terbagi lagi. Hal ini dikarenakan adanya perbedaan kondisi atau perbedaan faktor yang ada di dalam gaya tersebut. Gaya gesek yang terjadi antara dua benda padat dapat dibedakan menjadi dua macam gaya, yaitu:

\section{a. Gaya Gesek Statis}

Menurut Lohat (2008:389) gaya gesekan yang bekerja pada permukaan benda yang bersentuhan, ketika benda tersebut belum bergerak disebut gaya gesek statik. Dapat dikatakan bahwa gaya gesek merupakan gaya yang timbul sejak benda diberi gaya hingga sesaat sebelum benda mulai bergerak. Lambang dari gaya gesek ini adalah fs. Gaya gesek statis yang maksimum sama dengan gaya terkecil yang dibutuhkan agar benda dapat mulai bergerak. Ketika benda telah bergerak, gaya gesek antara dua permukaan akan berkurang sehingga diperlukan gaya yang lebih kecil agar benda bergerak dengan laju tetap.

\section{b. Gaya Gesek Kinetik}

Menurut Lohat (2008:392) gaya gesek kinetik adalah gaya yang bekerja pada dua permukaan benda yang bersentuhan ketika benda tersebut bergerak. Gaya gesek kinetic memiliki lambing fk. Ketika sebuah benda bergerak pada permukaan benda lain, gaya gesekan bekerja berlawanan arah terhadap kecepatan benda.

\section{Penerapan Gaya Gesek dalam Aspek yang Menguntungkan dan Merugikan}

Penerapan gaya gesek dalam kehidupan sehari-sehari seringkali dilakukan. Dalam penerapan gaya gesek, tentu bukan hanya aspek yang menguntungkan saja, tetapi besar kemungkinan gaya gesek menimbulkan aspek yang merugikan. Berikut ini adalah penerapan gaya gesek dalam aspek yang menguntungjan dan merugikan.

\section{a. Gaya gesek yang Menguntungkan}

1) Gaya gesek yang terjadi antara sepatu dengan permukaan tanah.

Saat kita sedang berjalan, terjadi sebuah proses aksi dan reaksi. Ketika telapak kaki mendorong tanah ke belakang, gesekan yang dikerjakan tanah pada telapak kaki akan mendorong tubuh ke depan. Apabila tanah dalah dalam keadaan licin, maka koefisien geseknya kecil sehingga gaya geseknya pun kecil sehingga memungkinkan kaki akan terpeleset. 
2) Gaya gesek pada roda kendaraan yang bergerigi

Seperti yang kita ketahui bahwa pada umumnya roda memiliki permukan yang bergerigi atau beralur. Hal ini bertujuan untuk memperbesar gaya gesek antara roda dengan tanah. Semakin besar gaya gesek maka kecil kemungkinan roda akan tergelincir khususnya pada tanah atau jalan yang licin. Jika roda tidak dibuat beralur atau bergerigi, maka gaya gesek yang dihasilkan akan semakin kecil, sehingga besar kmungkinan menyebabkan roda mudah tergelincir.

3) Gesekan pada korek api

Salah satu alat yang dapat menghasilkan api adalah korek api. Untuk menghasilkan korek api, perlu dilakukan gesekan antara pentol korek api dengan setrip samping kotak korek api. Gesekan yang dilakukan akan menyebabkan suhu pentol korek naik. Suhu panas tersebut menyebabkan bahan kimia pada pentol korek dengan setrip akan bereaksi. Suhu panas yang terus mengalami kenaikan akan menyebabkan korek api terbakar.

4) Gesekan antara amplas dan kayu

Amplas merupakan alat yang digunakan untuk menghaluskan permukaan benda-benda yang kasar. Amplas memiliki permukaan yang kasar sehingga ketika amplas digosokkan ke benda yang permukaannya kasar menghasilkan gaya gesek yang membuat permukaan benda menjadi halus.

5) Gesekan pada rem kendaraan

Saat kita ingin memperlambat atau menghentikan laju kendaraan, maka dilakukan sebuah pengereman. Rem sepeda biasanya berupa dua bantalan karet keras yang dipasang di setiap ujung ujung sisi penjepit rem. Penjepit kemudian diikat ke rangka sepeda dengan poros. Pada saat di rem, bantalan akan dijepit sehingga bergerak ke arah dalam hingga menekan pelek pada roda. Hal ini menimbulkan gaya gesek yang dapat memperlambat laju sepeda.

\section{b. Gaya Gesek yang Merugikan}

1) Gesekan antara ban kendaraan dengan aspal

Gesekan yang terjadi antara ban kendaraan dengan aspal akan menyebabkan panas pada ban. Selain itu, gesekan tersebut juga dapat menyebabkan permukaan ban semakin menipis. Ketika permukaan ban menipis maka gerigi pada ban akan semakin halus. Sehingga apabila digunakan, kendaraan akan mudah tergelincir karena gaya geseknya dengan aspal kecil.

2) Gesekan pada komponen mesin kendaraan

Saat mesin bekerja terjadi proses pembakaran yang menyebabkan mesin melakukan gerakan mekanik. Dalam gerakan ini, terjadi gesekan antar komponen mesin. Gesekan yang terjadi antar komponen mesin pada kendaaan akan menyebabkan mesin cepat panas, aus, dan membuat penggunaan bahan bakar menjadi boros. Untuk mengatasi ini, diperlukan pelumas, seperti oli yang berjuan untuk mengurangi gaya gesek yang tejadi antar mesin kendaraan sehingga mesin tidak mudah panas dan aus.

3) Gesekan antara udara dengan kendaraan

Saat kita mengendarai kendaraan, maka akan terjadi gaya gesek antara kendaraan yang kita kendarai dengan udara. Gaya yang terjadi tersebut tentunya akan memengaruhi kelajuan kendaraan. Jika gaya gesek yang dihasilkan besar, maka akan memperlambat laju kendaraan tersebut. Untuk dapat mempercepat laju endaraan maka dibutuhkan kinerja mesin yang ekstra dan bahan bahan bakar yang lebih banyak.

\section{Kesimpulan}

Gaya gesek adalah gaya yang berarah melawan gerak benda atau arah kecenderungan benda akan bergerak. Secara mikroskopis, gaya gesek disebabkan oleh interaksi melalui terbangunnya gaya ikat 
antara molekul-molekul yang berada dipermukaan satu benda dengan molekulmolekul pada permukaan benda yang lain ketika keduanya saling bersentuhan. Gaya gesek dapat digolongkan menjadi dua macam, yaitu gaya gesek statis dan gaya gesek mekanik. Gaya gesek tentu dapat diterapkan dalam kehidupan sehari-hari yang tentunya hal itu dapat membawa manfaat. Tetapi disamping itu, gaya gesek juga dapat menimbulkan dampa yang bersifat merugikan bagi kehidupan manusia.

\section{Daftar Pustaka}

Lohat, Sun Alexander. 2008. Gaya GesekanGesekan Statis dan Kinetis. Jakarta: Yudistira.

Riyadi, Agus. 2019. Gaya dan Gerak. Semarang: Alprin

Salim, Astuti dan Suryani Talib. 2017. Fisika Dasar 1. Yogyakarta: Deepublish

Sumarjono,dkk. 2005. Fisika Dasar 1. Malang: Universitas Negeri Malang

Trianto. 2010. Model Pembelajaran Terpadu. Surabaya: Bumi Aksara 